\title{
Technologies and Fabrication of Intelligent Packaging for Perishable Products
}

\author{
Lixing Wang ${ }^{1,2, *}$, Zhenning $\mathrm{Wu}^{1}$ and Changyong Cao ${ }^{2, *}$ \\ 1 School of computers and engineering, Northeastern University, \\ Shenyang 110000, China; wuzhenning@ise.neu.edu.cn \\ 2 Laboratory for soft Machines \& Electronics, School of packaging, Michigan State University, \\ East Lansing, MI 48824, USA \\ * Correspondence: wanglixing@mail.neu.edu.cn (L.W.); ccao@msu.edu (C.C.); Tel.: +86-185-2444-6209 (L.W.); \\ $+1-517-353-9504$ (C.C.)
}

Received: 7 October 2019; Accepted: 7 November 2019; Published: 13 November 2019

\begin{abstract}
The preservation of perishable products to maintain their quality is of paramount importance for food safety and security, and is attracting more attention due to increasing concerns regarding food quality, healthcare, and quality of life. Advances in technology and materials in recent years have led to the development and implementation of intelligent packaging for perishable products that can monitor or even control their quality in a supply chain. In this paper, the techniques used in intelligent packaging (i.e., indicators, sensors, and identification technology) and the major printing methods for fabricating electronics (i.e., inkjet printing, screen printing, and gravure printing) are reviewed with a focus on the packaging of perishable products. Although the high manufacturing costs pose a major challenge the commercialization and large-scale deployment of perishable products, it is expected that the technological progresses in printing electronics will significantly reduce the manufacturing cost of intelligent packaging to a threshold of acceptance by markets. In addition, the broad applications of intelligent packaging can facilitate the traction and monitoring of perishable products for better control of the product quality and improved management of the supply chain.
\end{abstract}

Keywords: intelligent packaging; smart packaging; printed electronics; perishable products; printing methods

\section{Introduction}

Perishable products such as seafood, fruits, and vegetables are important items used in the daily live so many people. One common characteristic of perishable products is that they have a short shelf life and are prone to decay. The consumption of such decayed perishable products may lead to illness or even death. In the United States, approximately 9000 deaths occur each year owing to diseases caused by spoiled perishable products [1]. In Spain, $0.06 \%$ of people suffer from diseases very year. Besides the health hazards, substantial economic loss is another grave concern in the supply chain of perishable products. Because of the ineffective management of perishable products in the supply chain, especially during transportation, almost one-third of the products intended for human consumption are lost or wasted annually [2,3]. The large volumes of food waste have also become a significant financial burden for the food industry in the supply chain $[4,5]$.

Packaging is essential for perishable products, as it protects them from contamination, damage, and decay along the supply chain [6]. There are two main techniques through which packaging can be improved: active packaging and intelligent packaging. Janjarasskul and Suppakul have reviewed both methods. They concluded that the two methods both helped in the monitoring and preserving of quality of perishable products [7]. Active packaging is an innovative packaging system that either 
releases substances into or absorbs substances from the perishable products or their surrounding environment to maintain their quality and to extend their shelf life. In the past, researchers primarily focused on active packaging, however, in recent years advances in information technology and demand on effective management along the supply chain have led to a shift in research focus to intelligent packaging $[6,8]$. There is a growing need for perishable product companies to enable the packaging of their products to include more information on the product status and the environment conditions inside or outside the package [8]. Hence, there is a strong need for the development of intelligent packaging for the perishable product industry to allow for the improved protection of product quality and reduced economic losses.

Intelligent packaging or smart packaging was defined as "a packaging system that is capable of carrying out intelligent functions (such as detecting, sensing, recording, tracing, communicating, and applying scientific logic) to facilitate decision making for the extension of shelf life, enhancement of safety, improved quality through the provision of information and to notify about possible problems" [9]. In Europe, the legal definition of "intelligent food contact materials and articles" is "materials and articles that monitor the condition of packaged food or the environment surrounding the food" [10]. The basic functions of an intelligent package include tracking the products, monitoring the surrounding environment, and communicating with the backend system or consumers. Consequently, intelligent packaging can provide consumers or food suppliers with the condition of a food product and its storage environment. Also, nearly warning signal is given when there is an abnormal occurrence [11].

The basic functions of traditional food packaging: protection, communication, convenience, and containment have been enriched by the new development of intelligent packaging [9]. Kerry et al. proposed that intelligent packaging systems must include three main technologies, i.e., (i) indicators, a more convenient way of informing consumers about the quality of the food; (ii) data carriers, for storage and distribution of data including tracking; and (iii) sensors, for the rapid and accurate quantification of the analyses [4]. There are some other intelligent tools that can be applied in addition to these main intelligent packaging techniques [12]. Holograms can help prevent counterfeiting-and at a lower cost than radio-frequency identification (RFID)tags, which is very useful in the pharmaceutical industry. Thermo chromic inks can change color in different temperatures, and can be used for beverage packaging or for microwavable products, allowing consumers to know whether the hot or cold product is ready to be served. Ghaani et al. reviewed the intelligent packaging technologies for food and showed the gap between its demand and its application in the market due to higher costs. Hence, future research should also address this problem to make intelligent systems commercially viable for the packaging of everyday commodities. It will be attractive to have packaging costs that are less than $10 \%$ of the total cost of the products [13]. The development in printing electronics for large scale fabrication will be important and the sole approach to reduce the cost of intelligent packaging.

To be better informed about the level of research interest in intelligent packaging, we looked at research records covering the last five years (2014-2018), using techniques such as keyword searches to explore the web of science database. As the numbers of publications identified using different keywords varied significantly, we carried out a normalization process, and have presented the data in Table 1, with publication trends illustrated in Figure 1. Looking at the data, we can see that there has been far more recent interest in intelligent packaging than in active packaging, with the main techniques used in intelligent packaging—sensors and printing — capturing more interest.

In this paper, two major aspects of the intelligent packaging system for perishable products are reviewed. In Section 2, the basic techniques for identification and sensing are discussed, including indicators, sensors, and identification technology. In Section 3, the printing techniques for fabricating electronics and some combinations of these techniques are presented, including inkjet printing, screen printing, and gravure printing. A brief conclusion is finally given in Section 4. 
Table 1. (a) Recent publications about intelligent packaging. (b) Recent publications about intelligent packaging after normalization.

\begin{tabular}{|c|c|c|c|c|c|}
\hline Keywords & 2014 & 2015 & 2016 & 2017 & 2018 \\
\hline \multicolumn{6}{|c|}{ (a) } \\
\hline Active Packaging & 2246 & 2636 & 2757 & 2628 & 2968 \\
\hline Intelligent Packaging & 483 & 718 & 815 & 1098 & 1292 \\
\hline Indicator and Intelligent Packaging & 14 & 23 & 31 & 29 & 40 \\
\hline Sensor and Intelligent Packaging & 208 & 280 & 306 & 412 & 521 \\
\hline Radio-frequency identification (RFID) and Packaging & 289 & 308 & 243 & 309 & 311 \\
\hline Printing and Intelligent Packaging & 29 & 35 & 46 & 61 & 80 \\
\hline \multicolumn{6}{|c|}{ (b) } \\
\hline Active Packaging & 0 & 0.540166 & 0.707756 & 0.529086 & 1 \\
\hline Intelligent Packaging & 0 & 0.290482 & 0.410383 & 0.760198 & 1 \\
\hline Indicator and Intelligent Packaging & 0 & 0.346154 & 0.653846 & 0.576923 & 1 \\
\hline Sensor and Intelligent Packaging & 0 & 0.230032 & 0.313099 & 0.651757 & 1 \\
\hline RFID and Packaging & 0.676471 & 0.955882 & 0 & 0.970588 & 1 \\
\hline Printing and Intelligent Packaging & 0 & 0.117647 & 0.333333 & 0.627451 & 1 \\
\hline
\end{tabular}

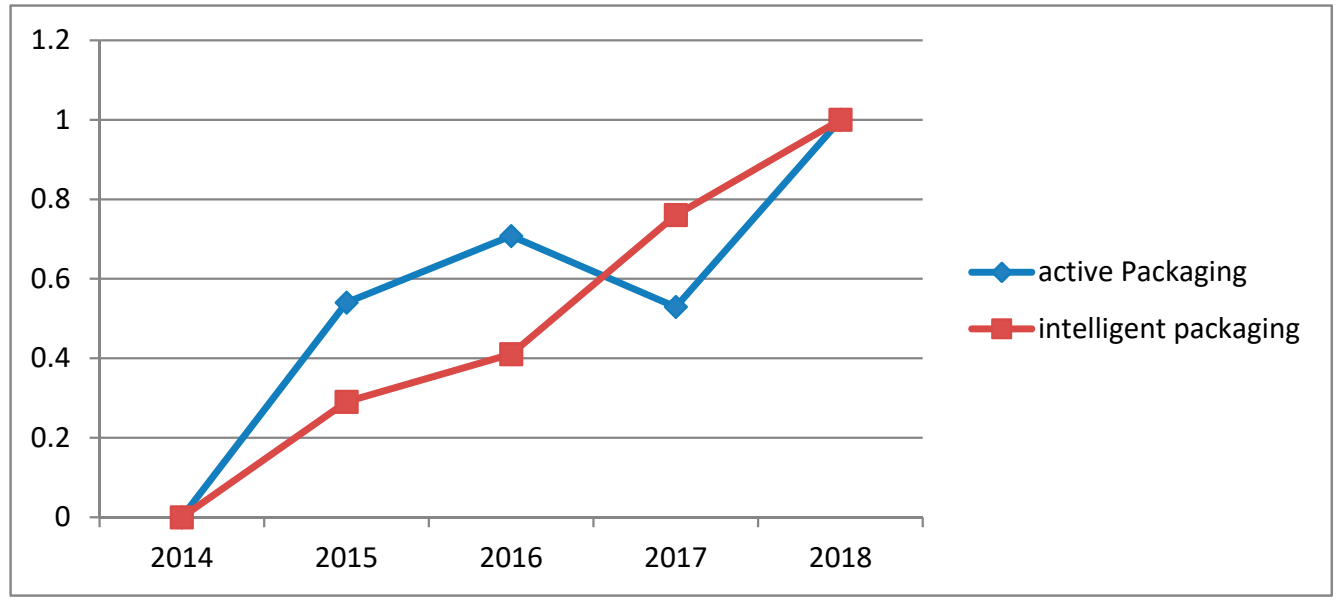

(a)

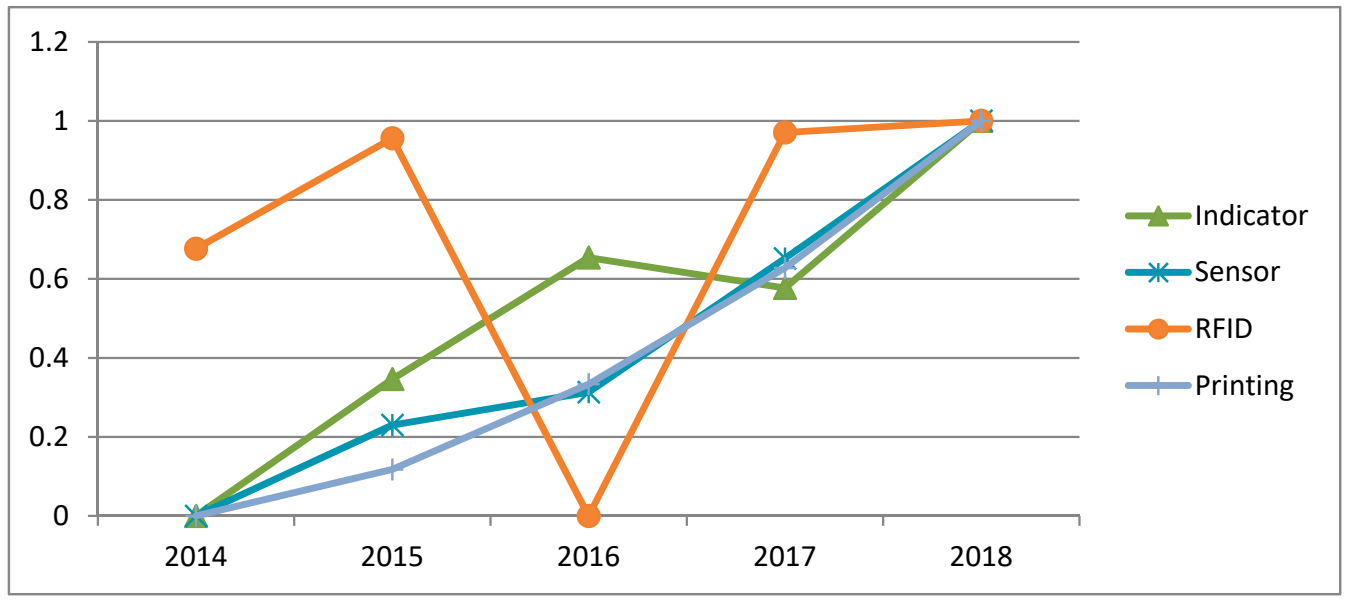

(b)

Figure 1. Publication trends: (a) active packaging and intelligent packaging (b) main techniques in intelligent packaging.

\section{Intelligent Packaging Techniques}

Different kinds of technologies have been utilized for developing intelligent packaging, targeting to track and identify products, monitoring the status of products for maintaining the quality of the 
products, while differentiating one product from another. In this section, identification techniques and sensing methods are mainly reviewed.

\subsection{Identification Techniques}

There are several stages of product identification. Writing the relevant product information or making marks on the package has been traditionally used for product identification. However, the absence of a single standard makes it a challenge to rapidly access the desired information on the product. In addition, it is challenging to record the information for all the parties of the supply chain.

The barcode is the most commonly used method for identification in the packaging industry, which consists of a series of identification numbers and black bars. Barcodes can be easily printed on the product's packaging through economical printing techniques. However, there are two limitations of this technique: the first one is that it needs an optical device to read the barcode, and avoid being obstructed, the second one is that the technique can only store a limited amount of information, which makes it difficult to record additional information about the product, such as contamination or the prescribed temperature of the environment. Thus, people invented another more advanced technology, known as radio-frequency identification (RFID).

RFID is a simple technique used for identification in intelligent packaging. In its read range, the RFID reader can automatically identify physical objects using radio-frequency signals by capturing the signal remotely from RFID tags. A typical RFID system is composed of an RFID tag, RFID reader, RFID antenna, and the backend system. The RFID tag is usually pasted on the packaging of the tracked item. The RFID reader and the antenna are usually connected by the cable. They function together to produce a magnetic field and to send and receive signals to and from RFID tags. The RFID reader can read and program the data stored on the RFID tags. A typical RFID system is illustrated in Figure 2.

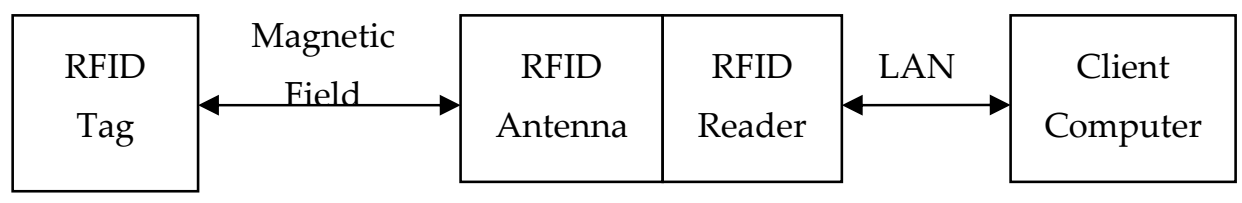

Figure 2. Schematic of atypical RFID System.

The Radio Frequency (RF) determines the type of applications that are best suited for an RFID system. RFs can be classified as listed in Table 2. A comparison between Barcodes and RFID is summarized in Table 3.

Table 2. Radio Frequency (RF) of an RFID System.

\begin{tabular}{cccc}
\hline Frequency & Read Range & Data Speed & Applications \\
\hline Low Frequency & $0-5 \mathrm{~cm}$ & Low & Emergency CardAccess Control \\
High Frequency, & $10 \mathrm{~cm}-1 \mathrm{~m}$ & Low to Moderate & ID CardsPayment \\
Ultra-High Frequency & $3 \mathrm{~m}-7 \mathrm{~m}$ & Moderate to High & Warehouse ManagementTracking \\
Microwave & $10 \mathrm{~m}-15 \mathrm{~m}$ (Passive) & High & Electronic Toll Collection \\
& $20 \mathrm{~m}-40 \mathrm{~m}$ (Active) & & Container Tracking \\
\hline
\end{tabular}

Table 3. Comparison between RFID and Barcodes.

\begin{tabular}{ccc}
\hline & Barcode & RFID \\
\hline Read Range & DirectlyWith no Obstacle & Longer \\
Price & Economical & Expensive \\
Read/Write Tag Data & No & Yes \\
\hline
\end{tabular}


RFID Tags: RFID tags are devices that contain identification information remotely transferred to anRFIDreader. The tag is composed of a simple silicon microchip and a small flat antenna. The microchip and the antenna are connected and implemented on a substrate. Based on the sources of energy, there are three types of RFID tags:

1. Active tags-They contain built-in batteries. These batteries provide power for broad casting signals to RFID readers, and there is no need to utilize power from the readers. This also allows them to communicate over a much larger distance than the other two types of RFID tags.

2. Semi-passive tags-They also contain built-in batteries. Compared to active tags, semi-passive tags have two statuses: active and sleep. In sleep status, the batteries do not work. When the tags receive the request from the RFID readers, the status changes from sleep to active. Then, the batteries begin to power the transmitter and receiver to broadcast the signal over a long communication distance.

3. Passive tags-They do not have batteries. For communication, the tags use the power derived from the magnetic field and generated by the reader. They then transfer the stored information back to the reader.

RFID Reader: The reader sends and receives radio frequency (RF) data to and from the tag using one antenna or several antennas. The reader is composed of a transmitter, receiver, and microprocessor.

Antennas: The antennas are usually connected to the RFID reader. They broadcast RF signals in the air and receive information from the RFID tags in the read range.

Host Computer System: The host computer system is a backend system. It acquires data from the RFID readers and routes the data to the correct application for processing into useful information.

The application of RFID has many benefits in intelligent packaging as it gives packaging the functionality of tracing and tracking, while preventing counterfeiting. For example, Papetti et al. proposed a RFID web-based info-tracking system for artisanal Italian cheese to obtain quality traceability. The system integrates the RFID technique with a non-destructive quality analysis system to evaluate the final quality based on the quality of a typical Italian cheese [14]. Barge et al. applied RFID to trace a dairy product. All item movements are automatically recorded during the production phase, handling in the maturing room and warehouse, delivery, packaging, and selling phases [15]. Wang et al. designed a supply-chain pedigree interactive dynamic explore (SPIDER) for food safety control based on an item level RFID traceability system [16].

Identification techniques play an important role in intelligent packaging for tracing and tracking; however, a lack of sensing functionality makes it difficult for the status of perishable products or their surrounding environment to be monitored. Hence, the sensing technique is another important part of intelligent packaging. In the next section, a brief introduction to sensing techniques in intelligent packaging is presented.

\subsection{Sensing Techniques}

Indicators and sensors are two main sensing technologies used in intelligent packaging to measure the product status or the surrounding environmental factors. Indicators are simple devices that have information about the product. This allows for the product status or environmental factors to be known in real-time from the packaging itself by observing it. There are three typical indicators: time-temperature indicators, gas indicators, and freshness indicators.

A time-temperature indicator (TTI) is a simple and inexpensive device. It is usually fixed on the packaging of products or shipping containers. By observing TTI on the packaging, consumers can directly know the measurable current at that instant or the historical environmental temperature based on the color changes, text display, etc. on the packaging of the products [17]. In the market, there are three types of TTIs: (1) critical temperature indicators that show warnings when the temperature is above or below a reference value, (2) partial history indicators that can display an indication when a product has been exposed to an environmental temperature that may result in a change in product quality, and (3) full history indicators that can provide all the historical environmental temperatures 
that a product has experienced [18]. Nemet et al. developed and patented a time and temperature dependent tamper-proof barcode indicator. Based on time and temperature dependent migration of the color particles, it allows the machine-readable barcode to change by printing the barcode using a specialized coloring agent [19].

Gas indicators are used to detect the gas condition in the packaging. Gasses can significantly affect the quality, safety, and integrity of perishables-for example, ethylene can promote fruit ripening, while shortening its shelf life. Gas indicators can either be small devices in the form of a package label, or they can be directly printed on packaging films for the purpose of monitoring [11]. Vu and Won developed a novel water-resistant UV-activated oxygen indicator for intelligent food packaging using alginate, a polymer that issued to prevent dyes from leaching out of colorimetric oxygen indicator films. However, the dye-based oxygen indicator film suffers from dye leaching upon contact with water [20].

Freshness indicators can show whether packaged goods are fresh or spoilt through changes in the color of a label or text on the package [1]. Chen et al. developed a colorimetric indicator label for monitoring the freshness of freshly-cut green bell peppers based on $\mathrm{pH}$-sensitive indicators [21]. Kuswandi et al. developed a simple colorimetric sensor to serve as an inexpensive visual indicator to monitor the freshness of a fish using PANI films. The PANI films are reusable and are regenerated using an acid solution [22]. Rukchon et al. developed a combined $\mathrm{pH}$ and dye-based colorimetric freshness indicator as a "chemical barcode" for the real-time monitoring of the spoilage of skinless chicken breasts [23].

Sensors are more complex than indicators and are commonly used in cases where the extensive historical status of products or surrounding environmental factors of perishable products must be known. Sensors are used to detect, locate, or quantify energy or matter by generating a signal following the detection or measurement of a physical or chemical property to which the device responds [24]. A typical sensor is composed of four parts: a receptor, a transducer, signal processing electronics, and a display unit. However, sensors used in intelligent packaging must also have a micro-controller, an external memory and a power source. The structure of a typical sensor is shown in Figure 3. In recent years, flexible sensors have received great attention for their role facilitating intelligent packaging of perishable products.

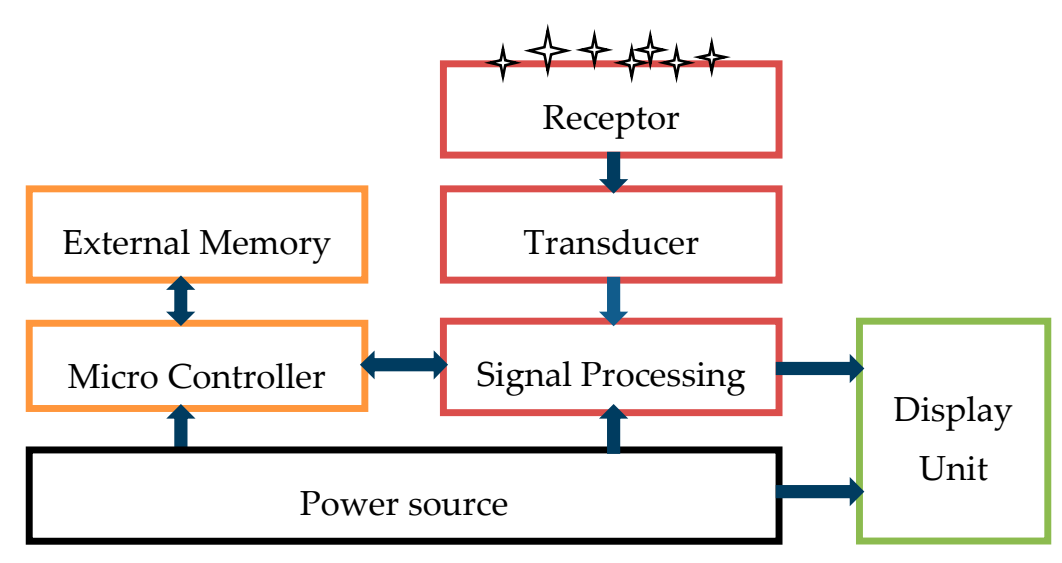

Figure 3. A typical architecture involving the sensors.

Puligundla et al. developed several different types of carbon dioxide $\left(\mathrm{CO}_{2}\right)$ sensors such as optical sensors, polymer opal films, and polymer hydrogels that could intelligently monitor the changes in concentration of gas inside the food package [25]. Mohammad et al. fabricated a highly flexible and low cost hydrogen $(\mathrm{H} 2)$ gas sensor using inclined and vertically aligned zinc oxide $(\mathrm{ZnO})$ nanorods. The $\mathrm{ZnO}$ nanorods fabricated using an affordable thin and highly flexible nylon substrate with a luminous flux of $15 \mathrm{~lm}$ using the hydrothermal method [26]. Wu et al. developed wireless ammonia sensors with a high performance using ammonia $\left(\mathrm{NH}_{3}\right)$ sensitive materials composed of rGO and nano-silver ink (Ag-ink) that were loaded on a high-gain microstrip patch antenna [27]. Mattana et al. 
developed a woven textile that had temperature and humidity sensors on flexible plastic stripes. Two different methods were used for the fabrication of the sensors: a conventional photolithography patterning technique, and inkjet-printing (presented here as an effective and low cost alternative. A comparative analysis of two different fabrication methods was conducted in reference [28]).

Flexible sensors can be fabricated by printing approaches for reducing the fabrication cost and the environmental impact of their production. For instance, Briand et al. proposed printing processes for the fabrication of flexible sensors and discussed the integration of printed sensing devices on smart RFID tags [29]. Indicators cannot provide quantitative information about the quantity of the packaged products and cannot store the measurement and time data. Indicators can only provide immediate visual and qualitative (or semi-quantitative) information about the packaged food by means of a color change, an increase in color intensity, or diffusion of a dye along a straight path [4]. They do not need batteries and they are cheaper than sensors. For future intelligent packaging systems, electronical sensors are currently considered to be the most promising and innovative technology compared with simple indicators $[8,30]$. However, such sensors need energy to power the devices and they are usually more expensive.

\subsection{RFID Coupling with Sensing Techniques}

Indicators and flexible RFID tags are regarded as the most commercially viable technologies that can be integrated in intelligent packaging [31].Recently, Lorite et al., (2017) developed a passive RFID/NFC sensor tag. The tag hada rectangular antenna coil ( $32 \mathrm{~mm}$ width, $51 \mathrm{~mm}$ height) and worked at $13.56 \mathrm{MHz}$. In the coil structure, the sensor tag IC, including its peripheral components, was placed. There was no battery in the RFID sensor tag. The sensor tag utilized power from the magnetic field generated by the RFID reader. Additional smart sensors can be connected with the passive RFID/NFC sensor tag by employing copper wires [32].

Combining sensors with RFIDs can overcome the limited functions of indicators, i.e., the RFID is used for product identification while the indicator is used to determine and display the products' current status. The data carrier does not record the products' historical status, though it can be detected by indicators. Consequently, in recent years, the main focus has been on the development of low-cost sensors that consume less power with RFID. This has allowed for a better management of the perishable products sold by retailers and giving consumers more quality information on the products. The three types of RFID tags are developed for different applications in practice.

\subsubsection{Active Tags Coupling with Sensors}

Active tags can be easily coupled with sensors, as they operate using batteries that can be used to drive the sensors. For example, a product called Device-to-Business (D2B ${ }^{\mathrm{TM}}$ ), developed by the HK Poly U RFID team, is a typical active RFID tag coupled with sensors and applied in Intelligent Packaging. The product eases communication between RFID devices and other devices. The D2B ${ }^{\mathrm{TM}}$ contains 433-MHz active RFID tags, a communication module, and sensors. The different types of sensors are chosen based on the requirements of the applications. The communication distance can be up to $60 \mathrm{~m}$. This device can be connected to various other devices, such as smartphones, RFID readers, personal computers, etc.

Environmental factors such as container boxes can be monitored using D2B ${ }^{\mathrm{TM}}$ devices embedded in packaging. If any extreme changes in the environmental conditions occur in the container, the operators will receive a warning from the device. This allows the operators to take the necessary measures to prevent loss or damage. A mobile terminal and D2B ${ }^{\mathrm{TM}}$ device embedded in a container box is shown in Figure 4. In addition to monitoring the environment in container boxes, a D2B ${ }^{\mathrm{TM}}$ device can also be used to locate and select specific products through utilizing its Pick-to-Light function. The function benefits the warehouse management in cases where the first in, first out (FIFO) principle is used [33]. 


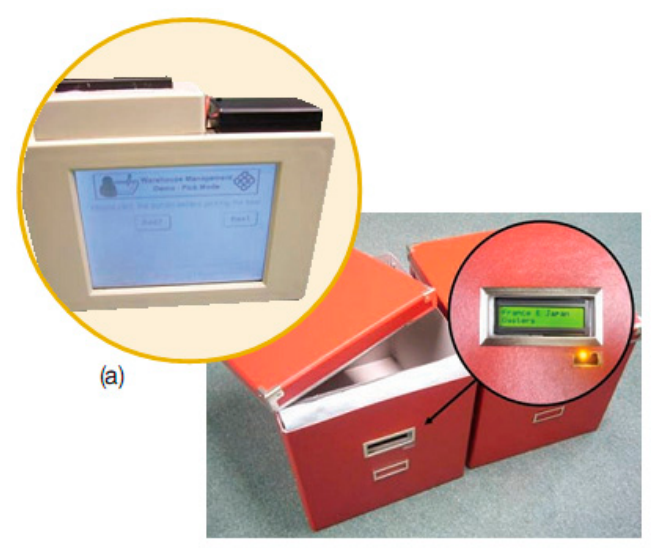

(b)

Figure 4. D2B ${ }^{\mathrm{TM}}$ device in the intelligent packaging.

\subsubsection{Semi-Passive Tags Coupling with Sensors}

Semi-passive tags coupled with sensors are comparable to active tags coupled with sensors; however, the only difference is that semi-passive tags must be activated when they need to function. Hence, they are not serving as real-time monitors because a signal must first activate the tags before the sensors connected to the tags can be read. A schematic of the first ISO 15693 compliant semi-active tag prototype is shown in Figure 5. It has low power control electronics, a RFID antenna, commercial sensors, a memory, and a thin film battery.

Abad et al., (2007) proposed and developed a flexible tag micro lab for food monitoring for the logistic chain. Their tag is a flexible label, hosting different sensor technologies with an RFID interface. The RFID interface is for the wireless exchange of data; thus, it can monitor the quality of food during transport, storage, and marketing. It works within a frequency of the $13.56 \mathrm{MHz}$ band as it is most suitable for flexible tag integration [34].

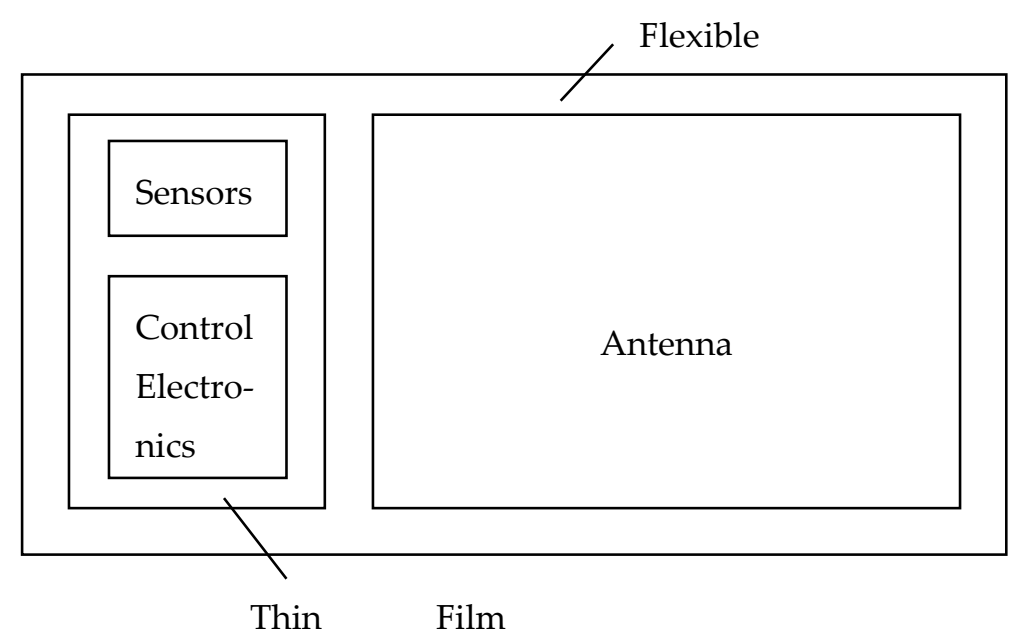

Figure 5. Main functional blocks of the semi-active tag.

\subsubsection{Passive Tags Coupling with Sensors}

Compared to passive sensors, the communication distance of the sensors with batteries are more extended, which enhances communication. However, the battery size limits the sensor size. The battery is not a flexible component, so sensors with batteries cannot be used as flexible sensors. Moreover, the battery has a limited life and needs to be replaced periodically $[35,36]$. These characteristics limit their applications in perishable product packaging [37,38], single-use 
biopharmaceutical manufacturing [39], and wearable electronics [35,40]. Thus, passive sensors are often used for the aforementioned applications because they are durable, cheap, easy to manufacture, and are inconspicuous devices [41].

Passive tags do not require batteries because they are powered by an electromagnetic field inducted by RFID readers. The coupled sensors also obtain their power from the signal sent by the RFID reader. This allows the device to work only when the reader is operational and well-functional, leading to a relatively longer life. However, the limited power generated by induction cannot support complicated sensors, and some sensors cannot function without communication with RFID reader during transportation.

Potyrailo and Surman developed a passive RFID-based sensor, in which they converted conventional high frequency (13.56 MHz) RFID tags into inductively coupled sensors. They acquired the resonance impedance spectrum of the RFID antenna to obtain digital sensor calibration parameters stored in an integrated circuit (IC) memory chip. They performed a multivariate analysis of the measured resonance impedance spectrum and extracted the relation between the sensor response and the gases of interest [42-44]. Poly ether urethane (PEUT) was used as the sensing material and was prepared by drop-casting a PEUT solution in dichloromethane, forming a 50- $\mu \mathrm{m}$ thick sensing film on a sensing antenna [45]. Later, Fiddes et al. proposed an innovative approach for modifying conventional RFID tags with chemically sensitive conductive composites by integrating them into the RFID tag circuit. In their design, maleic anhydride was used as a sensing material and the composite was able to detect different biogenic amines associated with food spoilage [46]. Recently, Zarifi et al. designed a chip less RFID sensor with a tag in a high-frequency structural simulator [47]. The sensor comprised a reader coil that was connected to a readout circuitry, a coil, and an interdigitated capacitor on the flexible tag. The reader generated a magnetic field to make the tags in the field transfer the sensing data to the readout circuitry. Bibi et al. developed a device that integrated the sensors in the design of UHF-RFID systems working at a frequency of $868 \mathrm{MHz}$. A natural polymer was selected for the sensor to monitor carbon dioxide in food packages [48].

Among these studies, the development of a smart tag that combines RFID and sensors is regarded as a better option for perishable product packaging. In such a design, the tag will use a sensor for measurement, RF for wireless communication, and its circuit for data storage. However, the relatively high costs of manufacturing such tags poses a great challenge for their commercial applications. The use of flexible printing techniques for fabricating these smart tags offers a practical method for reducing costs. The major printing techniques and printed RFID with sensor tags are described in the next section.

\section{Printing Techniques}

Printed electronics are fabricated with low cost organic based materials instead of traditional rigid silicon-based materials to make electronic devices via printing technologies. They have been widely used for a variety of emerging applications in flexible electronics, wearable electronics, and biodegradable electronics etc. [49]. The inexpensive fabrication of these electronics makes it possible for them to be included in the commercial application of intelligent packaging [50]. Nonhazardous biodegradable electronics and organic material shave great potential for the packaging of perishable products [31].

Printing methods can be classified based on two major approaches: contact and noncontact printing. In contact printing, the patterned components with inked surfaces are brought in physical contact with the substrate. In non-contact printing, on the other hand, the inks are dispensed through openings or nozzles together with predefined motions of the stage (substrate holder) following a pre-programmed pattern [51]. A promising example of contact printing is gravure printing and examples of noncontact printing include screen printing and inkjet printing. In recent years, the interest in the use of non-contact printing techniques has increased because they are simple, affordable, speedy, adaptable to the fabrication processes, reduce material wastage, and produce high resolution patterns that can be easily controlled by adjusting a few process parameters [52-57]. In addition, new and emerging 
polymeric stamp based printing methods such as nanoimprint, microcontact printing and transfer printing have also attracted significant interest, especially for the production of flexible electronics such as inorganic monocrystalline semiconductors [56-62].

\subsection{Inkjet Printing}

The main and popular non-contact printing in fabrication of flexible sensors is inkjet printing. It is a technique that uses a solute dissolved or dispersed in the solvent ink. A nozzle ejects acertain quantity of ink. And the ink dries up after the solvent evaporates. In the past few years, the applications for inkjet printing have grown and it can be used to print onto a wide variety of substrate materials such as conducting polymers [63-65], metallic layers [66,67], and bio-materials [68,69]. Figure 6 indicates a type of inkjet printing: thermal and piezoelectric inkjet system, which applies a pulse that enables the ejection of small droplets of ink. Inkjet printing can also be used to fabricate finely patterned and thin films of conducting polymers. Most printed sensors are fabricated using inkjet printing owing to its simple and digital layout design process.

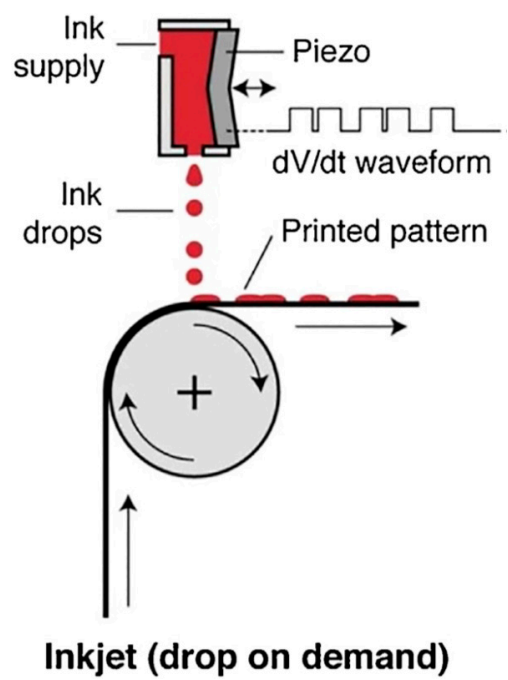

Figure 6. Schematic of the working principles of inkjet printing [53].

Lorwongtragool et al. fabricated a low-cost chemical sensor array with a ZigBee wireless communication module to detect and analyze armpit odor. For this application, this electronic nose should be wearable. It could measure fresh and native odors instantaneously. CNTs/polymer composites were used as sensing materials. The chemical sensor array was completely fabricated using inkjet-printing [70]. The electronic nose is a rapid detection device for food spoilage, and its installation on packaging is an effective way to monitor food quality [71]. Dua et al. developed a flexible and lightweight chemi-resistor to detect chemically aggressive vapors at parts per billion levels in an air sample at room temperature. The device was made of a thin film, and the film was fabricated using inkjet printing on flexible plastic surfaces [72]. Crowley et al. fabricated a sensor for the analysis of ammonia gas using inkjet printing for the deposition of polyaniline nanoparticle films. The sensor was further combined with heater foils for operation at a range of temperatures to monitor leakage of ammonia in a wide range of industrial applications. They also optimized the inkjet printed polyaniline nanoparticle sensor. An aqueous dispersion of the nanoPANI was deposited over a silver interdigitated array using a piezoelectric inkjet printer [73]. Rieu et al. recently applied inkjet printing on polyimide foil to fabricate a tin dioxide $\left(\mathrm{SnO}_{2}\right)$ sensor. Gold electrodes and heaters were printed on each side of the substrate. This was the first complete inkjet-printed metal oxide sensor printed on polymeric foil that included a gas-sensitive layer and a heating transducer [74]. Seekaew et al. presented a simple and low-costinkjet printing technique for fabricating an innovative flexible gas sensor made of a graphene-poly(3,4-ethylenedioxythiophene): poly(styrenesulfonate) (PEDOT:PSS) 
composite film with a high uniformity over a large area. Solution-processed graphene-PEDOT:PSS ink was used to inkjet-print onto a transparent substrate with prefabricated electrodes and used for $\mathrm{NH}_{3}$ detection at room temperature [49]. Wongchoosuk et al. fabricated a low-cost and flexible $\mathrm{NH}_{3}$ gas sensor using thermal ink-jet printing techniques [75]. These aforementioned flexible-printed sensors can also be applied to the intelligent packaging of perishable products. For packaging, Wu et al. applied inkjet printing for the fabrication of a "smart cap", which could be used to monitor the quality of liquid foods, such as milk or juice. All electrical components, including resistors, capacitors, and inductors, as well as circuits and passive wireless sensors, were printed [76]. Li et al. fabricated a fully inkjet-printed RFID sensor tag for humidity monitoring in intelligent packaging, with tests showing that the RFID sensor tag could be fabricated directly onto paper packaging in a single application [77].

\subsection{Screen Printing}

Screen-printing also belongs to non-contact printing technique. It is the most popular technology established in printing. The key components of a screen printer are the mesh and the squeegee. The squeegee makes the ink to travel through the opened pattern of the mesh to the substrate. It is used in the electronics industry to print metallic interconnects on printed circuit boards and has been in use for several years. It is faster and more versatile in comparison with other printing tools, as it is simple, affordable, and adaptable in the fabrication process [53,54,78-81].

Dubourg et al. fabricated a miniaturized resistive-type humidity sensor on a large-scale by printing it on a flexible substrate. The fabrication process involved two parts. The first part wasa laser ablation of the design of interdigitated electrodes on a polyethylene terephthalate (PET) substrate. The second part was the screen-printing process for the deposition of a sensitive material. This study introduced a new low-cost and low-temperature procedure that allowed for the large-scale fabrication of humidity sensors on flexible PET substrates. The result showed that the laser ablation was better suited for the patterning of interdigitated electrodes on a microscale, and the screen-printing was better suited for the industrial integration of metal-oxide-based sensitive films on flexible substrate [82]. Screen printing can be combined with inkjet printing in an electronics fabrication process. Fernández-Salmerón et al. used screen printing to apply a spiral inductor used as an RFID antenna, and inkjet printing to apply planar capacitive structures used to form LC resonators. A polyimide was chosen as the substrate and as the sensitive material [83].

\subsection{Gravure Printing}

Gravure printing is a contact printing technique. It entails the direct transfer of functional inks through physical contact of the engraved structures with the substrate [8] and provides higher resolution printing in comparison to noncontact printing. Thus, it may be used for the fabrication of printed devices with higher resistance and capacitance values. As shown in Figure 7, a gravure printer comprised a rolling cylinder and a printing cylinder. Firstly, the rolling cylinder is coated with copper. Following this, laser or electrochemical method is applied to engrave a pattern on the cylinder. The cylinder is then coated with a chrome layer for protection from wear and tear. The ink is introduced using an ink bath under the cylinder or a nozzle on top of the cylinder. A doctor's blade is applied to remove the excess ink. Finally, the ink is transferred to a rolling substrate [50]. Kuberský et al. developed the functional ammonia, humidity, and nitrogen dioxide sensors, which were fabricated by screen and gravure printing on flexible poly substrates [84]. Ammonia and humidity sensors were fabricated by gravure printing of organic-based sensitive layers on flexible PET foil while the nitrogen dioxide $\left(\mathrm{NO}_{2}\right)$ sensor was fabricated using screen printing.

These printing techniques have been successfully employed to fabricate various types of flexible sensors. Recently, studies have been carried out on fabrication of printed sensors, especially for intelligent packaging. Krivec et al. applied inkjet printing to fabricate an RFID packaging coupling with a surface acoustic wave (SAW) sensor chip. Nanoparticle Ag ink was used to print the antenna structure onto the polymer package. The SAW sensor chip was fixed into the chip cavity. The result 
showed that the SAW package had a significant wireless response when antenna interrogated using a continuous waveform radar reader unit [85]. Therefore, printing is apractical and feasible method for large-scale and cost-efficient fabrication of intelligent packaging.

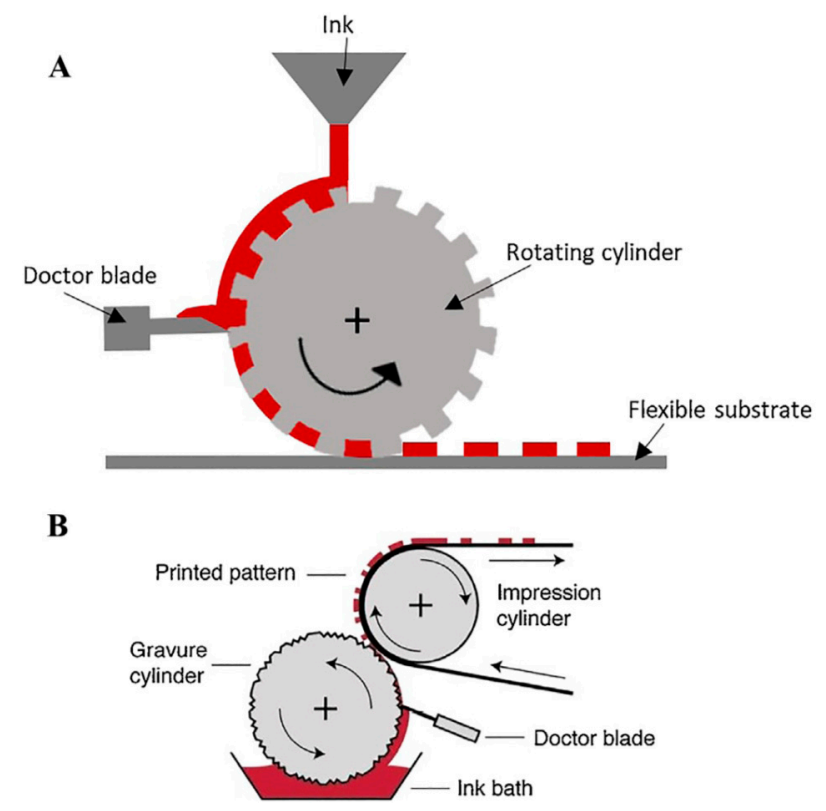

Figure 7. Schematic of working principles of gravure printing [53].

\section{Discussion}

As we mentioned above, cost is one of the main barriers for the commercialization of intelligent packaging. Besides costs, reliability is another important barrier keeping companies from using intelligent packaging - because if the packaging itself is not reliable, food safety becomes a matter of concern [86], and potentially serious consequences can arise from device shut-downs. Since intelligent packaging is a new concept, there are many factors that have not been taken into consideration for actual commercial applications. For example, light, temperature, or mechanical stress may have adverse effects on these technologies, potentially leading to incorrect results or undesired behaviors. To sum up, researchers still need to identify and resolve all the commercial application problems and to improve system robustness [12,87].

Food contact material is another limitation to the application of sensors in packaging. Most sensors, especially gas sensors, require contact with the food for accurate measurements. Countries have numerous regulations concerning the materials and articles intended to come into contact with food [88], and, unlike for the intelligent packaging used in other sectors, if it is necessary for the sensing node to come into contact with the food, then many common sensing materials cannot be used for intelligent packaging.

Recycling and cultural acceptance are two other reasons. People are accustomed to discarding the packages of products carelessly in the trash bin. But most intelligent packages need to be disposed carefully, because some components are harmful to the environment. And the waste caused by the unsuitable disposal of intelligent packaging is actually contradictory to the goal of reducing the amount of food wastage [31]. Furthermore, people are cautious when it comes to new technology, as was seen in the case of cameras in the 19th century or, more recently, transgenic foods-or even new vaccines. It also takes time for people to accept new technologies, and for governments to create the regulatory apparatus governing their application.

Overall, these issues indicate that intelligent packaging commercialization still has several barriers to overcome, and in our future studies, we will take greater account of these commercialization issues when considering intelligent packaging design. 


\section{Conclusions}

In conclusion, we have presented an overview of intelligent packaging for perishable products, focusing on main technologies, identification techniques, sensing techniques, and the combination of the various techniques of intelligent packaging. The identification techniques can help to track and trace products while the sensing techniques can help to monitor products. Coupled and integrated systems for the identification and sensing have the potential to improve the functionality of perishable product packages. With the globalization and rapid development in logistics, the supply chain of perishable products has become more complicated. There is a high demand to equip packaging with advanced intelligent functionality to track, trace, and monitor the products for better quality protection and long shelf life extension. This will motivate further research on intelligent packaging technologies and their broader applications.

Many factors affect the commercialization of intelligent packaging as we discussed in Section 4. It is expected that emerging printed sensors will become the mainstream for developing intelligent packaging and have the greatest potential to remove the cost limitations currently hindering their commercialization.

Author Contributions: L.W. and Z.W. conceived the ideas and designed the framework of the review; L.W. contributed to the identification and printing technologies; Z.W. contributed to the sensing technologies; L.W. prepared the draft; C.C. supervised the work and contributed to the manuscript writing and editing; all authors commented the manuscript.

Funding: This research was funded by the National Natural Science Foundation of China under Grant 71502029, Grant 61703087 and USDA National Institute of Food and Agriculture (Hatch Project 1016788).

Acknowledgments: The authors would acknowledge the support from Michigan State University, MSU AgBioResearch. We would like to thank the anonymous reviewers very much, as their comments and suggestions were very helpful in this paper's revision. We particularly appreciated the comments relating to additional barriers that must be overcome to facilitate market acceptance of intelligent packaging, as these make us further consideration about the topic.

Conflicts of Interest: The authors declare no conflict of interest.

\section{References}

1. Abreu, D.A.P.D.; Cruz, J.M.; Losada, P.P. Active and Intelligent Packaging for the Food Industry. Food Rev. Int. 2012, 28, 146-187. [CrossRef]

2. UN. World Health Organization: WHO Model Listsof Essential Medicines; WHO: Geneva, Switzerland, 2017.

3. Morris, M.A.; Padmanabhan, S.C.; Cruz-Romero, M.C.; Cummins, E.; Kerry, J.P. Development of active, nanoparticle, antimicrobial technologies for muscle based packaging applications. Meat Sci. 2017, 132, $163-178$. [CrossRef] [PubMed]

4. Kerry, J.P.; O'Grady, M.N.; Hogan, S.A. Past, current and potential utilisation of active and intelligent packaging systems for meat and muscle-based products: A review. Meat Sci. 2006, 74, 113-130. [CrossRef] [PubMed]

5. Parfitt, J.; Barthel, M.; Macnaughton, S. Food waste within food supply chains: Quantification and potential for change to 2050. Philos. Trans. R. Soc. B Biol. Sci. 2010, 365, 3065-3081. [CrossRef]

6. Schaefer, D.; Cheung, W.M. Smart Packaging: Opportunities and Challenges. Procedia CIRP 2018, 72, 1022-1027. [CrossRef]

7. Janjarasskul, T.; Suppakul, P. Active and intelligent packaging: The indication of quality and safety. Crit. Rev. Food Sci. Nutr. 2018, 58, 808-831. [CrossRef]

8. Kuswandi, B.; Wicaksono, Y.; Abdullah, A.; Heng, L.Y.; Ahmad, M. Smart packaging: Sensors for monitoring of food quality and safety. Sens. Instrum. Food Qual. Saf. 2011, 5, 137-146. [CrossRef]

9. Yam, K.L.; Takhistov, P.T.; Miltz, J. Intelligent packaging: Concepts and applications. J. Food Sci. 2005, 70, R1-R10. [CrossRef]

10. Communities TCotE. Regulation (EC) No. 1935/2004 of the European Parliament and of the Council of 27 October 2004 on materials and articles intended to come into contact with food and repealing Directives 80/590/EEC and 89/109/EEC. Off. J. Eur. Union. 2004, L338, 4. 
11. Fang, Z.; Zhao, Y.; Warner, R.; Johnson, S. Active and intelligent packaging in meat industry. Trends Food Sci. Technol. 2017, 61, 60-71. [CrossRef]

12. Sohail, M.; Sun, D.W.; Zhu, Z.W. Recent developments in intelligent packaging for enhancing food quality and safety. Crit. Rev. Food Sci. Nutr. 2018, 58, 2650-2662. [CrossRef] [PubMed]

13. Ghaani, M.; Cozzolino, C.A.; Castelli, G.; Farris, S. An overview of the intelligent packaging technologies in the food sector. Trends Food Sci. Technol. 2016, 51, 1-11. [CrossRef]

14. Papetti, P.; Costa, C.; Antonucci, F.; Figorilli, S.; Solaini, S.; Menesatti, P. A RFID web-based infotracing system for the artisanal Italian cheese quality traceability. Food Control 2012, 27, 234-241. [CrossRef]

15. Barge, P.; Gay, P.; Merlino, V.; Tortia, C. Item-level Radio-Frequency IDentification for the traceability of food products: Application on a dairy product. J. Food Eng. 2014, 125, 119-130. [CrossRef]

16. Wang, L.X.; Ting, J.S.L.; Ip, W.H. Design of Supply-chain Pedigree Interactive Dynamic Explore (SPIDER) for food safety and implementation of Hazard Analysis and Critical Control Points (HACCPs). Comput. Electron. Agric. 2013, 90, 14-23. [CrossRef]

17. Taoukis, P.S.; Labuza, T.P. Applicability of Time-Temperature Indicators as Shelf Life Monitors of Food Products. J. Food Sci. 1989, 54, 783-788. [CrossRef]

18. Singh, R.P. Scientific Principlesof Shelf Life Evaluation; Springer: Boston, MA, USA, 1994.

19. Nemet, Y. Tamper-Proof Quality Management Barcode Indicators. U.S. Patent 940,095,2B2, 26 July 2016.

20. Vu, C.H.T.; Won, K. Novel water-resistant UV-activated oxygen indicator for intelligent food packaging. Food Chem. 2013, 140, 52-56. [CrossRef]

21. Chen, H.Z.; Zhang, M.; Bhandari, B.; Guo, Z.M. Applicability of a colorimetric indicator label for monitoring freshness of fresh-cut green bell pepper. Postharvest Biol. Technol. 2018, 140, 85-92. [CrossRef]

22. Kuswandi, B.; Jayus Restyana, A.; Abdullah, A.; Heng, L.Y.; Ahmad, M. A novel colorimetric food package label for fish spoilage based on polyaniline film. Food Control 2012, 25, 184-189. [CrossRef]

23. Rukchon, C.; Nopwinyuwong, A.; Trevanich, S.; Jinkarn, T.; Suppakul, P. Development of a food spoilage indicator for monitoring freshness of skinless chicken breast. Talanta 2014, 130, 547-554. [CrossRef]

24. Kress-Rogers, E. Terms in instrumentation and sensors technology. In Instrumentationand Sensorsfor the Food Industry; Kress-Rogers, E., Ed.; Wood head Publishing Ltd.: Cambridge, UK, 1998.

25. Puligundla, P.; Jung, J.; Ko, S. Carbon dioxide sensors for intelligent food packaging applications. Food Control 2012, 25, 328-333. [CrossRef]

26. Mohammad, S.M.; Hassan, Z.; Talib, R.A.; Ahmed, N.M.; Al-Azawi, M.A.; Abd-Alghafour, N.M.; Chin, C.W.; $\mathrm{H}, \mathrm{N}$. Al-Hardan. Fabrication of a highly flexible low-cost $\mathrm{H} 2$ gas sensor using $\mathrm{ZnO}$ nanorods grown on an ultra-thin nylon substrate. J. Mater. Sci. Mater. Electron. 2016, 27, 1-9. [CrossRef]

27. Wu, B.; Zhang, X.; Huang, B.; Zhao, Y.; Cheng, C.; Chen, H. High-Performance Wireless Ammonia Gas Sensors Based on Reduced Graphene Oxide and Nano-Silver Ink Hybrid Material Loaded on a Patch Antenna. Sensors 2017, 17, 2070. [CrossRef]

28. Mattana, G.; Kinkeldei, T.; Leuenberger, D.; Ataman, C.; Ruan, J.J.; Molina-Lopez, F.; Quintero, A.V.; Nisato, G.; Tröster, G.; Briand, D.; et al. Woven Temperature and Humidity Sensors on Flexible Plastic Substrates for E-Textile Applications. IEEE Sens. J. 2013, 13, 3901-3909. [CrossRef]

29. Briand, D.; Molina-Lopez, F.; Quintero, A.V.; Ataman, C.; Courbat, J.; de Rooij, N.F. Why Going Towards Plastic and Flexible Sensors? Procedia Eng. 2011, 25, 8-15. [CrossRef]

30. Bagchi, A. Intelligent Sensing and Packaging of Foods for Enhancement of Shelf life: Concepts and Applications. Int. J. Sci. Eng. Res. 2012, 3, 1-13.

31. Vanderroost, M.; Ragaert, P.; Devlieghere, F.; De Meulenaer, B. Intelligent food packaging: The next generation. Trends Food Sci. Technol. 2014, 39, 47-62. [CrossRef]

32. Lorite, G.S.; Selkala, T.; Sipola, T.; Palenzuela, J.; Jubete, E.; Viñuales, A.; Cabañero, G.; Grande, H.J.; Tuominen, J.; Uusitalo, S. Novel, smart and RFID assisted critical temperature indicator for supply chain monitoring. J. Food Eng. 2017, 193, 20-28. [CrossRef]

33. Kwok, S.K.; Ng, P.H.; Choy, K.L. Development of an RFID-based Intelligent e-Seal System for Container and Physical Asset Management. Annu. J. IIE 2008, 28, 70-81.

34. Abad, E.; Zampolli, S.; Marco, S.; Scorzoni, A.; Mazzolai, B.; Juarros, A.; Gómez, D.; Elmi, I.; Cardinali, G.C.; Gómez, J.M.; et al. Flexible tag microlab development: Gas sensors integration in RFID flexible tags for food logistic. Sens. Actuators B Chem. 2007, 127, 2-7. [CrossRef] 
35. Pantelopoulos, A.; Bourbakis, N.G. A Survey on Wearable Sensor-Based Systems for Health Monitoring and Prognosis. IEEE Trans. Syst. Man Cybern. Part C 2010, 40,1-12. [CrossRef]

36. Patel, S.; Park, H.; Bonato, P.; Chan, L.; Rodgers, M. A review of wearable sensors and systems with application in rehabilitation. J. Neuroeng. Rehabil. 2012, 9, 21. [CrossRef] [PubMed]

37. Tao, H.; Brenckle, M.A.; Yang, M.; Zhang, J.; Liu, M.; Siebert, S.M.; Averitt, R.D.; Mannoor, M.S.; McAlpine, M.C.; Rogers, J.A.; et al. Silk-Based Conformal, Adhesive, Edible Food Sensors. Adv. Mater. 2012, 24, 1067-1072. [CrossRef] [PubMed]

38. Potyrailo, R.A.; Nagraj, N.; Tang, Z.; Mondello, F.J.; Surman, C.; Morris, W. Battery-free Radio Frequency Identification (RFID) Sensors for Food Quality and Safety. J. Agric. Food Chem. 2012, 60, 8535-8543. [CrossRef] [PubMed]

39. Potyrailo, R.A.; Surman, C.; Monk, D.; Morris, W.G.; Wortley, T.; Vincent, M.; Diana, R.; Pizzi, V.; Carter, J.; Gach, G.; et al. RFID sensors as the common sensing platform for single-use biopharmaceutical manufacturing. Meas. Sci. Technol. 2011, 22, 082001. [CrossRef]

40. Kim, D.H.; Lu, N.; Ma, R.; Kim, Y.S.; Kim, R.H.; Wang, S.; Wu, J.; Won, S.M.; Tao, H.; Islam, A.; et al. Epidermal Electronics. Science 2011, 333, 838-843. [CrossRef]

41. Potyrailo, R.A.; Surman, C.; Nagraj, N.; Burns, A. Materials and Transducers Toward Selective Wireless Gas Sensing. Chem. Rev. 2011, 111, 7315-7354. [CrossRef]

42. Potyrallo, R.A.; Morris, W.G. Multianalyte chemical identification and quantitation using a single radio frequency identification sensor. Anal. Chem. 2007, 79, 45-51. [CrossRef]

43. Potyrailo, R.A.; Surman, C.; Morris, W.G.; Go, S.; Lee, Y.; Cella, J.; Chichak, K.S. Selective quantitation of vapors and their mixtures using individual passive multivariable RFID sensors. In Proceedings of the 2010 IEEE International Conference on RFID, Orlando, FL, USA, 14-16 April 2010.

44. Diamond, D.; Coyle, S.; Scarmagnani, S.; Hayes, J. Wireless sensor networks and chemo-/biosensing. Chem. Rev. 2008, 108, 652-679. [CrossRef]

45. Potyrailo, R.A.; Surman, C. A passive radio-frequency identification (RFID) gas sensor with self-correction against fluctuations of ambient temperature. Sens. Actuators B Chem. 2013, 185, 587-593. [CrossRef]

46. Fiddes, L.K.; Chang, J.; Yan, N. Electrochemical detection of biogenic amines during food spoilage using an integrated sensing RFID tag. Sens. Actuators B Chem. 2014, 202, 1298-1304. [CrossRef]

47. Zarifi, M.H.; Deif, S.; Daneshmand, M. Wireless passive RFID sensor for pipeline integrity monitoring. Sens. Actuators A Phys. 2017, 261, 24-29. [CrossRef]

48. Bibi, F.; Guillaume, C.; Gontard, N.; Sorli, B. Wheat gluten, a bio-polymer to monitor carbon dioxide in food packaging: Electric and dielectric characterization. Sens. Actuators B Chem. 2017, 250, 76-84. [CrossRef]

49. Seekaew, Y.; Lokavee, S.; Phokharatkul, D.; Wisitsoraat, A.; Kerdcharoen, T.; Wongchoosuk, C. Low-cost and flexible printed graphene-PEDOT: PSS gas sensor for ammonia detection. Org. Electron. 2014, 15, 2971-2981. [CrossRef]

50. Yousefi, H.; Su, H.M.; Imani, S.M.; Alkhaldi, K.; Filipe, C.D.M.; Didar, T.F. Intelligent Food Packaging: A Review of Smart Sensing Technologies for Monitoring Food Quality. ACS Sens. 2019, 4, 808-821. [CrossRef] [PubMed]

51. Khan, S.; Lorenzelli, L.; Dahiya, R.S. Technologies for Printing Sensors and Electronics Over Large Flexible Substrates: A Review. IEEE Sens. J. 2015, 15, 3164-3185. [CrossRef]

52. Pease, R.F.; Chou, S.Y. Lithography and other patterning techniques for future electronics. Proc. IEEE. 2008, 96, 248-270. [CrossRef]

53. Sondergaard, R.R.; Hosel, M.; Krebs, F.C. Roll-to-Roll fabrication of large area functional organic materials. J. Polym. Sci. Part B Polym. Phys. 2013, 51, 16-34. [CrossRef]

54. Tobjork, D.; Osterbacka, R. Paper Electronics. Adv. Mater. 2011, 23, 1935-1961. [CrossRef]

55. Leenen, M.A.M.; Arning, V.; Thiem, H.; Steiger, J.; Anselmann, R. Printable electronics: Flexibility for the future. Phys. Status Solidi A Appl. Mater. Sci. 2009, 206, 588-597. [CrossRef]

56. Subramanian, V.; Chang, J.B.; Vornbrock, A.D.L.F.; Huang, D.C.; Jagannathan, L.; Liao, F.; Mattis, B.; Molesa, S.; Redinger, D.R.; Soltman, D.; et al. Printed Electronics For Low-Cost Electronic Systems: Technology Status and Application Development. In Proceedings of the ESSCIRC 2008-34th European Solid-State Circuits Conference, Edinburgh, UK, 15-19 September 2008.

57. Moonen, P.F.; Yakimets, I.; Huskens, J. Fabrication of Transistors on Flexible Substrates: From Mass-Printing to High-Resolution Alternative Lithography Strategies. Adv. Mater. 2012, 24, 5526-5541. [CrossRef] [PubMed] 
58. Choi, K.H.; Khan, S.; Dang, H.W.; Doh, Y.H.; Hong, S.J. Electrohydrodynamic Spray Deposition of ZnO Nanoparticles. Jpn. J. Appl. Phys. 2010, 49, 05EC08. [CrossRef]

59. Krebs, F.C. Fabrication and processing of polymer solar cells: A review of printing and coating techniques. Sol. Energy Mater. Sol. Cells. 2009, 93, 394-412. [CrossRef]

60. Perelaer, J.; Smith, P.J.; Mager, D.; Soltman, D.; Volkman, S.K.; Subramanian, V.; Korvinkdf, J.; Schubert, U.S. Printed electronics: The challenges involved in printing devices, interconnects, and contacts based on inorganic materials. J. Mater. Chem. 2010, 20, 8446-8453. [CrossRef]

61. Choi, M.C.; Kim, Y.; Ha, C.S. Polymers for flexible displays: From material selection to device applications. Prog. Polym. Sci. 2008, 33, 581-630. [CrossRef]

62. Sun, Y.G.; Rogers, J.A. Inorganic semiconductors for flexible electronics. Adv. Mater. 2007, 19, 1897-1916. [CrossRef]

63. Bharathan, J.; Yang, Y. Polymer electroluminescent devices processed by inkjet printing: I. Polymer light-emitting logo. Appl. Phys. Lett. 1998, 72, 2660-2662. [CrossRef]

64. Ballarin, B.; Fraleoni-Morgera, A.; Frascaro, D.; Marazzita, S.; Piana, C.; Setti, L. Thermal inkjet microdeposition of PEDOT: PSS on ITO-coated glass and characterization of the obtained film. Synth. Met. 2004, 146, 201-205. [CrossRef]

65. Yoshioka, Y.; Jabbour, G.E. Desktop inkjet printer as a tool to print conducting polymers. Synth. Met. 2006, 156, 779-783. [CrossRef]

66. Lee, H.H.; Chou, K.S.; Huang, K.C. Inkjet printing of nanosized silver colloids. Nanotechnology 2005, 16, 2436-2441. [CrossRef]

67. Lee, K.J.; Jun, B.H.; Kim, T.H.; Joung, J. Direct synthesis and inkjetting of silver nanocrystals toward printed electronics. Nanotechnology 2006, 17, 2424-2428. [CrossRef]

68. Okamoto, H.; Asamitsu, K.; Kamatani, N.; Okamoto, T. Reciprocal modulation of transcriptional activities between HIV-1 tat and MHC class II transactivator CIITA. Biochem. Biophys. Res. Commun. 2000, 279, 494-499. [CrossRef] [PubMed]

69. Xu, T.; Jin, J.; Gregory, C.; Hickman, J.J.; Boland, T. Inkjet printing of viable mammalian cells. Biomaterials 2005, 26, 93-99. [CrossRef] [PubMed]

70. Lorwongtragool, P.; Sowade, E.; Watthanawisuth, N.; Baumann, R.R.; Kerdcharoen, T. A Novel Wearable Electronic Nose for Healthcare Based on Flexible Printed Chemical Sensor Array. Sensors 2014, 14, 19700-19712. [CrossRef]

71. Poghossian, A.; Geissler, H.; Schoning, M.J. Rapid methods and sensors for milk quality monitoring and spoilage detection. Biosens. Bioelectron. 2019, 140, 18-31. [CrossRef]

72. Dua, V.; Surwade, S.P.; Ammu, S.; Agnihotra, S.R.; Jain, S.; Roberts, K.E.; Park, S.; Ruoff, R.S.; Manohar, S.K. All-Organic Vapor Sensor Using Inkjet-Printed Reduced Graphene Oxide. Angew. Chem. Int. 2010, 49, 2154-2157. [CrossRef]

73. Crowley, K.; Morrin, A.; Hernandez, A.; O’Malley, E.; Whitten, P.G.; Wallace, G.G.; Smyth, M.R.; Killard, A.J. Fabrication of an ammonia gas sensor using inkjet-printed polyaniline nanoparticles. Talanta 2008, 77, 710-717. [CrossRef]

74. Rieu, M.; Camara, M.; Tournier, G.; Viricelle, J.P.; Pijolat, C.; de Rooij, N.F.; Briand, D. Fully inkjet printed $\mathrm{SnO} 2$ gas sensor on plastic substrate. Sens. Actuators B Chem. 2016, 236, 1091-1097. [CrossRef]

75. Wongchoosuk, C.; Jangtawee, P.; Lokavee, P.; Udomrat, S.; Sudkeaw, P.; Kerdcharoen, T. Novel Flexible NH3 Gas Sensor Prepared by Ink-Jet Printing Technique. Adv. Mater. Res. 2012, 506, 39-42. [CrossRef]

76. Wu, S.Y.; Yang, C.; Hsu, W.; Lin, L. 3D-printed microelectronics for integrated circuitry and passive wireless sensors. Microsyst. Nanoeng. 2015, 1, 15013. [CrossRef]

77. Feng, Y.; Xie, L.; Chen, Q.; Zheng, L.R. Low-Cost Printed Chipless RFID Humidity Sensor Tag for Intelligent Packaging. IEEE Sens. J. 2015, 15, 3201-3208. [CrossRef]

78. Krebs, F.C.; Jorgensen, M.; Norrman, K.; Hagemann, O.; Alstrup, J.; Nielsen, T.D.; Fyenbo, J.; Larsen, K.; Kristensen, J. A complete process for production of flexible large area polymer solar cells entirely using screen printing-First public demonstration. Sol. Energy Mater. Sol. Cells. 2009, 93, 422-441. [CrossRef]

79. Turunen, R.; Nakayama, M.; Numakura, D. Screen printing for high-density flexible electronics. Print. Circuit Des. Manuf. 2007, 24, 44.

80. Kwack, Y.J.; Choi, W.S. Screen-printed Source-drain Electrodes for a Solution-processed Zinc-tin-oxide Thin-film Transistor. J. Korean Phys. Soc. 2011, 59, 3410-3413. [CrossRef] 
81. Chang, W.Y.; Fang, T.H.; Yeh, S.H.; Lin, Y.C. Flexible Electronics Sensors for Tactile Multi-Touching. Sensors 2009, 9, 1188-1203. [CrossRef]

82. Dubourg, G.; Segkos, A.; Katona, J.; Radović, M.; Savić, S.; Niarchos, G.; Tsamis, C.; Crnojević-Bengin, V. Fabrication and Characterization of Flexible and Miniaturized Humidity Sensors Using Screen-Printed TiO 2 Nanoparticles as Sensitive Layer. Sensors 2017, 17, 1854. [CrossRef]

83. Fernandez-Salmeron, J.; Rivadeneyra, A.; Rodriguez, M.A.C.; Capitan-Vallvey, L.F.; Palma, A.J. HF RFID Tag as Humidity Sensor: Two Different Approaches. IEEE Sens. J. 2015, 15, 5726-5733. [CrossRef]

84. Kuberský, P.; Syrový, T.; Hamáček, A.; Nešpůrek, S.; Stejskalc, J. Printed Flexible Gas Sensors based on Organic Materials. Procedia Eng. 2015, 120, 614-617.

85. Krivec, M.; Roshanghias, A.; Abram, A.; Binder, A. Exploiting the combination of 3D polymer printing and inkjet Ag-nanoparticle printing for advanced packaging. Microelectron. Eng. 2017, 176, 1-5. [CrossRef]

86. Kalpana, S.; Priyadarshini, S.R.; Maria Leena, M.; Moses, J.A.; Anandharamakrishnan, C. Intelligent packaging: Trends and applications in food systems. Trends Food Sci. Technol. 2019, 93, 145-157. [CrossRef]

87. Manthou, V.; Vlachopoulou, M. Bar-code technology for inventory and marketing management systems: A model for its development and implementation. Int. J. Prod. Econ. 2001, 71, 157-164. [CrossRef]

88. Muller, P.; Schmid, M. Intelligent Packaging in the Food Sector: A Brief Overview. Foods 2019, 8, 16. [CrossRef] [PubMed]

(C) 2019 by the authors. Licensee MDPI, Basel, Switzerland. This article is an open access article distributed under the terms and conditions of the Creative Commons Attribution (CC BY) license (http://creativecommons.org/licenses/by/4.0/). 